\title{
2D Model of Capillary Transport of Water in Aerated Concrete
}

\author{
Ondřej Šikula ${ }^{a}$, Martin Mohapl
}

\author{
Faculty of Civil Engineering, Brno University of Technology, Czech Republic \\ asikula.o@fce.vutbr.cz, ${ }^{\mathrm{b}}$ mohapl.m@fce.vutbr.cz
}

Keywords: moisture of materials, capillary transport, aerated concrete, numerical model

\begin{abstract}
Aerated concrete from the viewpoint of the transport of liquid moisture appears to be a material with highly variable properties strongly dependent on the porosity and liquid water exposure conditions. Saturation degree of aerated concrete strongly affects not only all its thermaltechnical properties, but regarding to the risk freezing, also the strength properties. To predict the degree of saturation and moisture distribution, we used certain mathematical and physical methods supplemented with experimentally identified parameters. The aim of this paper is to discuss existing approaches to model capillary moisture transport in aerated concrete and description of the new, simplified 2D computer mathematical-physical model for the solution of this phenomenon. The results of the model are compared with experiments carried out. The conclusion discusses the limits of this new model, and mentions further possibilities for its improvement.
\end{abstract}

\section{Introduction}

Water in liquid or gaseous state fundamentally affects structural and technical properties of building constructions. Theoretical models of moisture transport in materials allow prediction of moisture interaction impact on utility properties. Presently, the aerated concrete is widely used material which is also very absorbent and therefore we took them as the subject of our study pointing on its behavior during flooding. Moisture transfer mechanisms are diffusion and convection of water vapor, capillarity and convection of liquid water caused by gravity - see [7]. Several experimental methods and physical models describing moisture transfer in liquid and gaseous form in porous material can be found. When the material is flooded, faster penetration of water to material caused by hydrostatic pressure can be expected. To determine amount of water and its position in time, direct or indirect methods may be used, sometimes using of destructive methods is necessary [3]. Behavior of material during surface sorption and capillary conduction is strongly dependent on the character of its contact with liquid water. In a case of load caused by rain (we neglect heavy rain driven against material by high velocity) or placing of material in water surface only free saturation of material by to value $u_{f}\left[\mathrm{~kg} / \mathrm{m}^{3}\right]$ is present. When the pressure is involved, saturation of material is significantly greater which takes place with higher intensity. Maximum saturation of material is then the boundary value $u_{\max }$. According to Holm et al. [2], total volumetric water content is 2.5 times greater than free saturation, i.e. up to $80 \%$ by volume. Mass flow of water $m_{w}\left[\mathrm{~kg} / \mathrm{m}^{3}\right]$ at free capillarity is approximately given by $m_{w}=A \sqrt{ }_{\tau}$ according to [3], penetration depth of moisture wave head $X[\mathrm{~m}]$ is then given by following equation $X=B \vee_{\tau}$. Both of these equations are simple, however they depend on one parameter (A respectively B), this parameter may be determined only by one form of contact with water, which reduces its usability in other cases. Description of water transport in area with free saturation is even more complicated. Results of this experiment show [5] that between the area of saturation and super saturation by water, difference in capillary pressures does not occurre and therefore transport of liquid water almost does not exist. From this fact authors deduce that the water content gradient $d u / d x$ is not suitable potential for description of water transport above the point of free saturation. Krus and Künzel suggest relative humidity as a suitable potential. Gradient of relative humidity $d \varphi / d x$ Künzel also uses as a potential for moisture transport in WUFI software - see [4]. The problem of using relative humidity is its limitation to the value $100 \%$ which is the value for free saturation of material by water, therefore this potential cannot 
describe increased capillary transport of water to the material due to hydrostatic pressure for example. Using this case, the increased moisture transport has to be described by transport coefficient which would lead to physically utterly inconvenient model. From the above mentioned, we can see that software WUFI is not able to solve effect of hydrostatic pressure of the water on material surface and it can be further used only for comparing of results from experiment on free capillarity. The most correct physical model is based on liquid water movement as a result of effect of pressure gradients - see [1], however it is very difficult to experimentally determine transport coefficient of liquid water with this potential - see [7]. To determine liquid sorption coefficient $D_{w}\left[\mathrm{~m}^{2} / \mathrm{s}\right]$, many authors use flow of water through material $q_{w}\left[\mathrm{~kg} /\left(\mathrm{m}^{2} \cdot \mathrm{s}\right)\right]$ defined by Kirscher: $q_{w}=D_{w(u)} \cdot d u / d x$ - see [3]. Experimental determination of transport coefficient is based on calculation of this coefficient from the above mentioned equation. This coefficient is extremely dependent on specific water content. It highly increases with increasing moisture content $u$ and previous experimental measurements of $D_{w}$ in area of super saturation differ in order magnitudes as we can see in [5]. Our first aim was to determine liquid transport coefficient $D_{w}$ in sorption area. We also tested various simplified formulas. Constant behavior of liquid transport coefficient was proven to be unsatisfactory as well as the approximately exponential behavior which is mentioned in [8]. Function inspired by the shape of sorption curve according [8] was proven unsatisfactory too. Slight improvement was reached by using approximation function which we obtained from least squares method, but results with below mentioned experiment did not agree sufficiently. The last option was to use a piecewise continuous linear function which consists of 5 segments and by iteration it is possible to find such a behavior when the results from calculation will agree with experimentally obtained results.

\section{Used methods}

For the solution we chose method of computer and laboratory experiment. The computer experiment was performed using newly developed numerical model - see below. In order to determine behavior of liquid transport coefficient we conducted two experiments using four samples of aerated concrete with dimensions of $120 \times 120 \times 120 \mathrm{~mm}$ - see fig. 1 - the case A - free capillarity and case B - immersion with hydrostatic pressure of $10 \mathrm{kPa}$. In this experiment we put hydroinsulating coating on all the surfaces except the bottom one in a way to ensure the same surface through which water can penetrate into the sample during both cases. Continuously, using weighing method we determined and recorded water content in samples. We also measured the heights into which water arose in samples surface. After one day, we vertically cut one samples for each case and in this section we determined depth of penetration and head shape of moisture wave. Dashed lines present expected behavior of head in time, for case A see fig. 1 a). For theoretical solution of free capillarity we developed own 2D numerical computational model in MS Excel. Own model is based on following presumptions:

- soaking of water due to capillarity and ambient pressure is dependent on Fick's diffusion;

- transport of liquid moisture has dominant influence on water amount and therefore diffusion of water vapor is neglected;

- effect of temperature on water transport is neglected due to approximately constant temperatures during laboratory measurements;

- moisture transfer coefficient $\beta\left[\mathrm{kg} /\left(\mathrm{m}^{2} \mathrm{~s}\right)\right]$ on surfaces is assumed to be constant.

Moisture transfer coefficient is bonded with heat transfer coefficient - see [1]. Paper [6] presents effect of heat transfer coefficient on speed of aerated concrete drying and from its results is apparent that speed of drying $\left[\mathrm{kg} /\left(\mathrm{m}^{2} \mathrm{~h}\right)\right]$ arises by $68 \%$ when heat transfer coefficient arises from 5 to $10 \mathrm{~W} /\left(\mathrm{m}^{2} . \mathrm{K}\right)$. Under the laboratory conditions, heat transfer coefficient is assumed to be stationary in time and constant on the surface, therefore constant coefficient of moisture transfer $\beta$ was chosen. Own model is based on numerical solution of differential equation (1) by finite volume method according to [9]. Where $\tau$ means time [s], and $u$ is the specific water content $\left[\mathrm{kg} / \mathrm{m}^{3}\right]$. 


$$
\frac{\partial u}{\partial \tau}=\frac{1}{\partial x}\left(D_{w}(u) \frac{\partial u}{\partial x}\right)+\frac{1}{\partial y}\left(D_{w}(u) \frac{\partial u}{\partial y}\right)
$$

Boundary conditions are moisture transfer coefficient $\beta_{1}=10^{-3} \mathrm{~kg} /\left(\mathrm{m}^{2} \mathrm{~s}\right)$ and equilibrium moisture of aerated concrete $u_{(R H)}=5 \mathrm{~kg} / \mathrm{m}^{3}$ which is almost $50 \%$ of RH (relative humidity) of air in the laboratory.

a) Case A (capillarity)

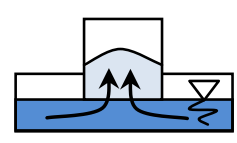

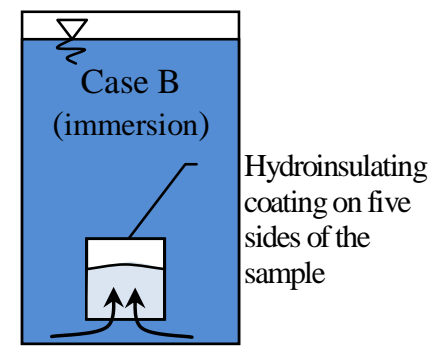

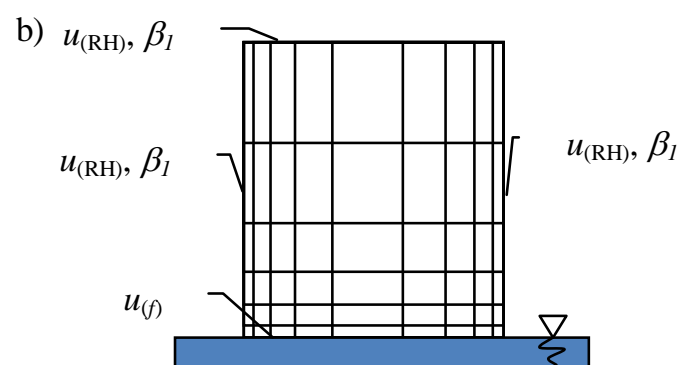

Fig. 1 - Schema of a) experiment, b) grid and boundary conditions of own 2D model - case A

Simulations were carried out in own model as well as in software WUFI for comparison of case A capillarity - see fig. 1 a). Initial moisture for simulation was chosen uniformly in entire volume of cross section $-5.3 \mathrm{~kg} / \mathrm{m}^{3}$, specific water content in free capillarity of value $u_{f}=370 \mathrm{~kg} / \mathrm{m}^{3}$ was taken from [5] for bulk density of aerated concrete $\rho=570 \mathrm{~kg} / \mathrm{m}^{3}$. Real evaluated bulk density of used samples is $\sim 600 \mathrm{~kg} / \mathrm{m}^{3}$. Our aim was to find such behavior of $D_{w(u)}$ to obtain results from own model which agree with experiments. We also compared the results with simulation in WUFI.

\section{Results}

Figure 2 a) shows iteratively calculated course of liquid transport coefficient $D_{w}$ in area of free capillarity. Figure $2 \mathrm{~b}$ ) shows the results of own model, software WUFI and both experiments cases A, B.
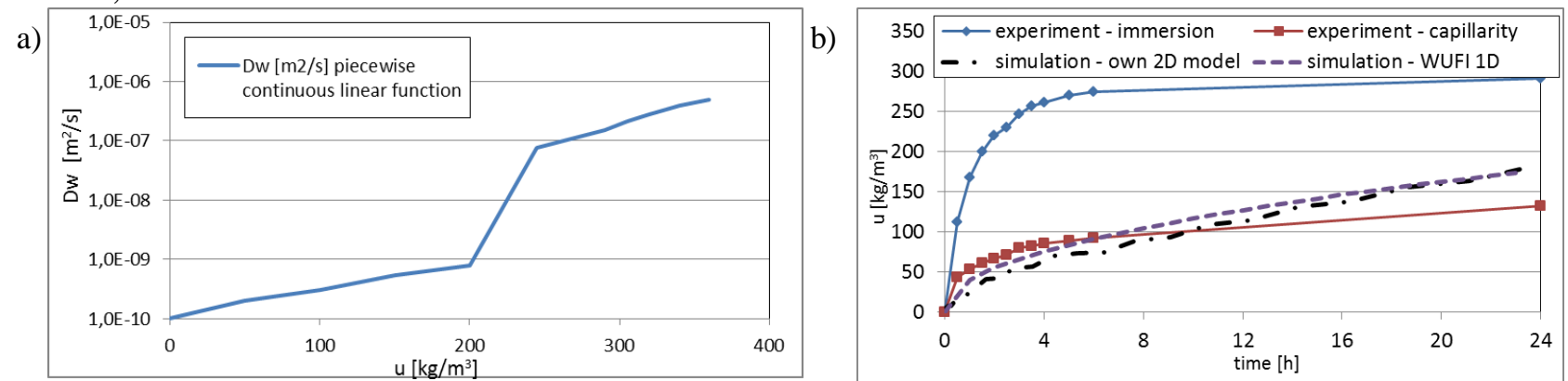

Fig. 2 - a) course of liquid transport coefficient, b) comparison of moistening

Head of moisture wave penetrated into the depth of $5 \mathrm{~cm}$ near the surface and into $6 \mathrm{~cm}$ in the axis of sample after 24 hours. These results compared with results obtained from own model agree well (penetration into the depth of $5.5 \mathrm{~cm}$ in the axis of sample) - see fig. 6 . In the fig. 5 we can see very good agreement of own model with WUFI software which was validated. On the other hand agreement with experiment is smaller. We can also see faster increase of water content in case B comparing to the case A. After cutting the sample in case B we visually determined its full water saturation although from slight slope of moistening curve - see fig. 5 we can see that sample was still able to absorb water. 
a)

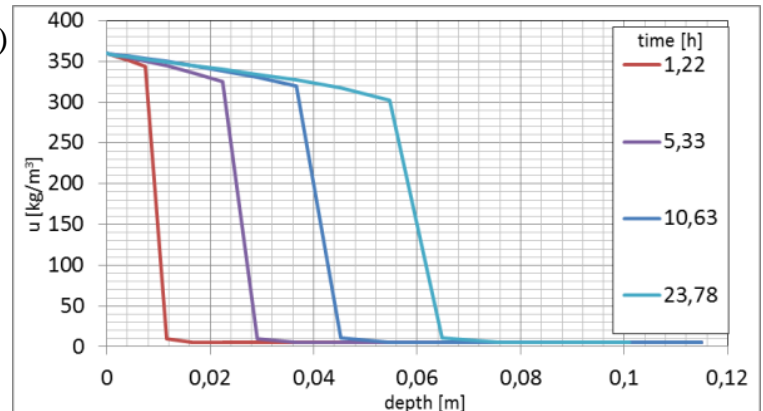

b)

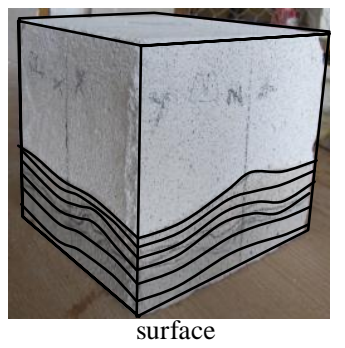

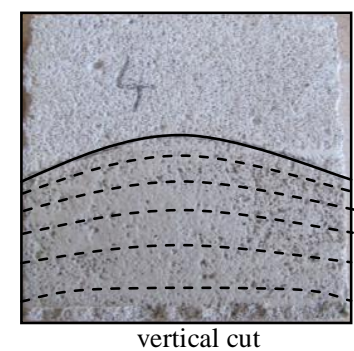

Fig. $6-a)$ water penetration into the depth of material, $b$ ) moistening during the case $A$

\section{Discussion}

Results of experiment shows higher intensity of water transport in aerated concrete due to hydrostatic pressure - case B comparing with case A - capillarity. Differences in results can be partially caused by 3D reality against 2D model and also by the value of $u_{f}=370 \mathrm{~kg} / \mathrm{m}^{3}$ which was used in both simulations. Regarding to the experimentally obtained results this value may appear exaggerated. Better agreement can be expected using lower value of coefficient $u_{f}$.

\section{Conclusion}

It can be remarked that both used models - and any other to our knowledge - are not able to determine the effect of hydrostatic pressure of water. Another research taking into account this phenomenon will be conducted in order to simulate flooding of material.

\section{Acknowledgment}

This paper has been supported from Specific Research at The Brno University of Technology, grant no. FAST-J-12-1781 and No. CZ.1.05/2.1.00/03.0097, as an activity of the regional Centre AdMaS.

\section{References}

[1] R. H. Peuhkuri, C. Rode, Moisture Dynamics in Building Envelopes. (BYG-Rapport; No. R071), 2003.

[2] M. Krus, Feuchtetransport und Speicherkoeffizienten poröser mineralischer Baustoffe Theoretische Grundlagen und neue Messtechniken. Dissertation Universität Stuttgart 1995.

[3] A. Holm, M. Krus, H.M. Künzel, Approximation der Feuchtespeicherfunktion aus einfach bestimmbaren Kennwerten. IBP-Mitteilung 29. Frauenhofer Institut für Bauphysik. 2002.

[4] H.M. Künzel, Verfahren zur ein- und zweidimensionalen Berechnung des gekoppelten Wärmeund Feuchtetransports in Bauteilen mit einfachen Kennwerten. Dissertation Universität Stuttgart 1994.

[5] H. Janssen, J. Carmeliet, H. Hens, The influence of soil moisture transfer on building heat loss via the ground. Build Environ. 2004; 39(7):825-836.

[6] M. Krus, H.M. Künzel, Flüssigtransport im Übersättigungsbereich. IBP-Mitteilung 22. Frauenhofer Institut für Bauphysik. 1995.

[7] M. Krus, A. Holm, Approximationsverfahren für die Bestimmung feuchtetechnischer Materialkennwerte. Frauenhofer Institut für Bauphysik.

[8] M. Krus, K. Lenz, R. Plagge, G. Scheffler, Ein Trocknungskoeffizient als neuer hygrothermischer Standardmaterialkennwert.

[9] S.V. Patankar, Numerical Heat Transfer and Fluid Flow, Hemisphere Publishing Corporation, New York, 1980. 